\title{
Bacterial community succession and chemical profiles of subtidal biofilms in relation to larval settlement of the polychaete Hydroides elegans
}

\author{
Hong Chun Chung ${ }^{1}$, On On Lee ${ }^{1}$, Yi-Li Huang ${ }^{2}$, Siu Yan Mok ${ }^{1}$, Roberto Kolter ${ }^{2}$ \\ and Pei-Yuan Qian ${ }^{1}$ \\ ${ }^{1}$ KAUST Global Partnership Program, Department of Biology, The Hong Kong University of Science and \\ Technology, Kowloon, Hong Kong SAR, China and ${ }^{2}$ Department of Microbiology and Molecular Genetics, \\ Harvard Medical School, Harvard University, Boston, MA, USA
}

\begin{abstract}
Earlier studies have shown that biofilms can mediate the larval settlement of the polychaete Hydroides elegans and that changes in the bacterial community structure and density of biofilms often alter the larval settlement response. However, the chemical cues that mediate this response remain unknown. In this study, both successional changes in the bacterial community structure and the chemical profiles of subtidal biofilms are described and related to the larval settlement response. Multispecies biofilms were developed on polystyrene Petri dishes and granite rock in the subtidal zone over a period of 20 days. The effects of the substratum and age on the bacterial community structure and chemical profiles of the biofilms were evaluated with two molecular methods (microarray (PhyloChip) and denaturing gradient gel electrophoresis) and with gas chromatography-mass spectrometry, respectively. Both age and substratum altered the bacterial community structures and chemical profiles of the biofilms. Age had a greater effect in shaping the bacterial community structure than did the substratum. In contrast, the type of substratum more strongly affected the chemical profile. Extracts of biofilms of different ages, which developed on different substrata, were tested for the settlement of $\boldsymbol{H}$. elegans larvae. The extracts induced larval settlement in a biofilm-age-dependent manner, and extracts originating from different substrata of the same age showed no differences in larval settlement. Our results suggest that the larval settlement response cannot be predicted by the overall chemical composition of the biofilm alone. The ISME Journal (2010) 4, 817-828; doi:10.1038/ismej.2009.157; published online 21 January 2010
\end{abstract}

Subject Category: microbial ecology and functional diversity of natural habitats

Keywords: biofilm succession; chemical profile; bacterial community structure; larval settlement; Hydroides elegans

\section{Introduction}

Biofilms are agglomerates of macromolecules and microorganisms, including bacteria, diatoms, fungi, and protozoa, enmeshed in a matrix of extracellular polymeric substances (Decho, 2000; Marshall and Bowden, 2000). It has been suggested that they are both inductive (Mitchell and Maki, 1988; Wieczorek et al., 1996; Harder et al., 2002a; Huang and Hadfield, 2003; Qian et al., 2003) and inhibitive mediators (Maki et al., 1988; Wieczorek and Todd, 1997) of larval settlement for a number of fouling benthic species. Of the different biofilm components, the community structure and ecological functions of the bacteria have been most intensively studied (Smart et al., 2008; Monds and O'Toole,

Correspondence: P-Y Qian, Department of Biology, The Hong Kong University of Science and Technology, Clear Water Bay, Kowloon, Hong Kong SAR, China.

E-mail: boqianpy@ust.hk

Received 30 September 2009; revised 7 December 2009; accepted 21 December 2009; published online 21 January 2010
2009). Studies have increasingly focused on explaining how the bacterial community structure of natural (multispecies) biofilms mediates larval settlement in the field. The bacterial communities of natural biofilms vary in their responses to environmental factors such as salinity, temperature (Lau et al., 2005), tidal level (Qian et al., 2003; Dobretsov and Qian, 2006), dissolved oxygen (Nocker et al., 2007), and habitat (Chiu et al., 2007; Hung et al., 2007). Natural biofilms formed under different environmental conditions vary in their attractiveness to settling larvae (Lau et al., 2005; Dobretsov and Qian, 2006; Chiu et al., 2007; Hung et al., 2007). Earlier studies have provided evidence that bacterial community structure is important for settling larvae, but the actual settlement cues associated with biofilm communities remain unknown.

Chemically mediated larval settlement has been observed in many benthic species (Pawlik, 1992; Tamburri et al., 1992; Steinberg et al., 2002), but the cues examined in these studies are not necessarily ecologically relevant. 
Biofilms are rich sources of chemical cues (Steinberg et al., 2002). Recently, two compounds that induce the settlement of the polychaete Hydroides elegans have been isolated from a 6-days-old (6d) natural biofilm (Hung et al., 2009): a long-chain fatty acid (12-octadecenoic acid) and a hydrocarbon (6,9heptadecadiene) induced larval settlement to a similar extent as the natural biofilm. To date, few studies have documented changes in the chemical compositions of natural biofilms through community succession. We hypothesize that in addition to changes in the bacterial community structure, changes in the chemical composition of the biofilm should also be a very important attribute to biofilm bioactivity.

To test the above hypothesis, we investigated the successional changes in both the bacterial community structures and chemical profiles of natural subtidal biofilms on different substrata. To explore the link between larval settlement and the bacterial community structures and chemical profiles of natural biofilms, we also examined whether chemical extracts of these biofilms induced the larval settlement of $H$. elegans.

\section{Materials and methods}

Biofilm development

Multispecies biofilms were developed on polystyrene Petri dishes and granite rock panels in Port Shelter, Hong Kong $\left(22^{\circ} 19^{\prime} \mathrm{N}, 114^{\circ} 16^{\prime} \mathrm{E}\right)$ in November 2007 , over a period of 20 days. Polished granite rock panels $(0.3 \times 0.3 \mathrm{~m})$ and polystyrene Petri dishes (60 mm in diameter; Falcon \#1006, Becton Dickinson, Franklin Lakes, NJ, USA) attached to identical granite rock panels were covered with a $125 \mu \mathrm{m}$ mesh to prevent the settlement of marine invertebrates, and were submerged to a subtidal level $(-0.5 \mathrm{~m})$. During the succession period, the replicate biofilms that developed on the granite rock and Petri dishes were retrieved at intervals of 3 days for the first 12 days and then at intervals of 4 days for the last 8 days. They were then transported to the laboratory in autoclaved filtered $(0.22 \mathrm{~mm})$ seawater (AFSW), and dip-rinsed 10 times in AFSW to remove any loosely attached particles and bacteria. Throughout the paper, 'young biofilms' refer to 3-9-days-old (3-9d) biofilms and 'old biofilms' refer to 12-20-days-old (12-20d) biofilms.

\section{Bacterial density in biofilms}

Biofilms of different ages were fixed with $4 \%$ of formalin and then stained with the DNA-binding fluorochrome 4,6-diamidino-2-phenylindole. The bacterial density was counted under an epifluorescence microscope at a magnification of $\times 1000$ $(n=3)$. For biofilms developed on the granite rock panels, the bacterial cells were collected from a surface area equal to that of the Petri dishes $(n=3)$ using a sterile cell scraper, and were resuspended in
AFSW and captured on a $0.22 \mu \mathrm{m}$ black polycarbonate filter (Millipore, Bedford, MA, USA). The filter was then fixed, stained, and viewed as described above. Two-way analysis of variance was used to compare the bacterial density data among different samples.

Bacterial community profiling by denaturing gradient gel electrophoresis

The biofilms were collected from the Petri dishes ( $n=5$ at each time point of the succession) and from equal surface areas of granite rock using sterile cotton buds, which were then frozen in $0.8 \mathrm{ml}$ of DNA extraction buffer $(100 \mathrm{mM}$ Tris-HCl, $100 \mathrm{mM}$ $\mathrm{Na}_{2}$-EDTA, $100 \mathrm{mM} \mathrm{Na}_{2} \mathrm{HPO}_{4}, 1.5 \mathrm{M} \mathrm{NaCl}$, and $1 \%$ cetyl trimethylammonium bromide at $\mathrm{pH}$ 8). The bacterial genomic DNA was extracted with a standard sodium dodecyl sulfate-based extraction protocol (Zhou et al., 1996). Bacterial communities in the biofilm samples were analyzed by denaturing gradient gel electrophoresis (DGGE) according to the procedures described by Lau et al. (2005). The $16 \mathrm{~S}$ rRNA genes (16S rDNA) in the crude DNA extracts were amplified by PCR using the universal primers 341F-GC (Muyzer et al., 1996) and 907R (Ishii et al., 2000) under the following PCR conditions: $95{ }^{\circ} \mathrm{C}$ for $2 \mathrm{~min}$; 10 touchdown cycles of $95^{\circ} \mathrm{C}$ for $1 \mathrm{~min}, 65{ }^{\circ} \mathrm{C}$ (reduced to $55^{\circ} \mathrm{C}$ in increments of $1{ }^{\circ} \mathrm{C}$ per cycle) for $1 \mathrm{~min}$, and $72{ }^{\circ} \mathrm{C}$ for $1 \mathrm{~min}$; 15 cycles at a constant annealing temperature of $55^{\circ} \mathrm{C}$ for $1 \mathrm{~min}$ and $72^{\circ} \mathrm{C}$ for $5 \mathrm{~min}$. As the bacterial communities from replicate samples showed no significant differences on preliminary DGGE runs (Supplementary Figure 2) and the number of samples that could be loaded onto a DGGE gel was limited, the genomic DNAs from three replicate samples were pooled for DGGE analysis. The PCR products were resolved on a $1 \mathrm{~mm}$ thick vertical gel containing $4 \%$ $(\mathrm{w} / \mathrm{v})$ polyacrylamide (37.5:1 acrylamide:bisacrylamide) with a linear gradient of $30-80 \%$ denaturant. Electrophoresis ( $125 \mathrm{~V}$ for $18 \mathrm{~h}$ ) was performed in $1 \times$ TAE buffer (Tris-acetate-EDTA), maintained at $60^{\circ} \mathrm{C}$. The DNA bands were stained with SYBR Gold (Molecular Probes, Eugene, OR, USA) and visualized with an Alphaimager 2000 (Alpha Innotech, San Leandro, CA, USA). The DGGE band positions and intensities were determined with the GelCompar II software (Applied Maths, Austin, TX, USA), with manual modifications. The bands were matched with $1 \%$ position tolerance and $1 \%$ optimization. The similarity matrix was calculated based on the Pearson coefficient and used to construct a dendrogram (Clarke and Warwick, 2001) with the PRIMER version 3.1 program (Plymouth Marine Laboratory, Plymouth, UK).

Bacterial community profiling by PhyloChip analysis The bacterial community structure was also analyzed with another molecular method, PhyloChip analysis (Bodrossy and Sessitsch, 2004). The 
16S rDNA amplicons were amplified from the pooled DNA under the conditions described above, except that the forward primer used lacked a GC clamp. The amplicons were purified using a PCR purification kit (Takara Inc., Dalian, China). Pooled replicates from $6 \mathrm{~d}$ (representing young biofilms) and 12d biofilms (representing old biofilms) developed on Petri dishes were used for the PhyloChip analysis to determine the taxonomic composition of the young and old bacterial communities in greater detail. For each samples, $250 \mathrm{ng}$ of purified $16 \mathrm{~S}$ rDNA amplicons was spiked with an internal standard composed of known concentrations of amplicons derived from prokaryotic metabolic genes and synthetic 16S-like genes (Brodie et al., 2007). The internal standard allowed the comparison of the arrays and the normalization of any interarray variation. The DNA mixture of the biofilm amplicons and internal standard was fragmented to 50-200 bp with DNase1 (0.02 $\mathrm{U} \mathrm{\mu g}^{-1}$ DNA; Invitrogen, Carlsbad, CA, USA) in $10 \times$ DNase1 buffer (USB, Cleveland, OH, USA), according to the Affymetrix protocol (Affymetrix, Santa Clara, CA, USA). The fragmented material was then labeled with biotin using GeneChip DNA labeling reagent (Affymetrix) and terminal deoxynucleotide transferase (Promega, Madison, WI, USA), according to their corresponding manufacturer's instructions. Before hybridization to the PhyloChip, an aliquot of the labeled DNA was denatured at $99^{\circ} \mathrm{C}$ for $5 \mathrm{~min}$. The hybridization reaction was carried out at $48^{\circ} \mathrm{C}$ for $16 \mathrm{~h}$ with shaking at 60 r.p.m. All washing and scanning with a GeneArray Scanner (Affymetrix) was performed under the conditions described by Brodie et al. (2006). Probe pairs that met the following two criteria were scored as positive: (1) the fluorescence intensity of the perfectly matched probe was at least 1.3 times greater than the intensity of the mismatched control; and (2) the difference in intensity, perfectly matched minus mismatched control, was at least 130 times greater than the squared noise value $\left(>130 N^{2}\right)$ (Brodie et al., 2007). The positive fraction (PosFrac) was calculated for each probe as the number of positive probe pairs divided by the total number of probe pairs in a probe set. A taxon was considered 'present' when its PosFrac was 0.95 or greater. The data were analyzed using Phylotrac. Each taxon detected was described by a single representative species.

Chemical composition profiling by gas chromatography-mass spectrometry

The biofilms were collected from the Petri dishes $(n=40)$ and from equal surface areas of the granite rock at each time point in the succession with sterile cotton buds and extracted twice with $100 \mathrm{ml}$ of a 1:1 mixture of dichloromethane (DCM) and methanol at room temperature for $8 \mathrm{~h}$ with gentle agitation. The extracts from the same time points were combined and filtered through Whatman filter paper No. 1, and then evaporated to dryness under vacuum. The crude extract was then dissolved in the appropriate solvents for chemical profile analysis and bioassay, as described below.

For chemical profile analysis using gas chromatography-mass spectrometry (Varian/CP-3800 and Varian/Saturn 2200), the crude biofilm extracts were partitioned into polar and nonpolar fractions. The crude extract was resuspended in 10 volumes of DCM, and partitioned three times with an equal volume of MilliQ water. The DCM extract was dried by rotary evaporation in vacuo at $35{ }^{\circ} \mathrm{C}$ and the MilliQ water extract was freeze-dried. The partitioned extracts were derivatized according to (Drozd and Novak, 1982). The derivatized extracts were injected into a relatively nonpolar capillary column (CP-Sil 8 CB-MS; $30 \mathrm{~m}$ length, $0.25 \mu \mathrm{m}$ film thickness, $0.25 \mathrm{~mm}$ ID; Varian, Palo Alto, CA, USA). The temperature gradients used were initially from 65 to $120^{\circ} \mathrm{C}$ in increments of $10^{\circ} \mathrm{Cmin}^{-1}$ and then from 120 to $310^{\circ} \mathrm{C}$ in increments of $12{ }^{\circ} \mathrm{Cmin}^{-1}$, with a subsequent constant temperature of $310^{\circ} \mathrm{C}$ for $10 \mathrm{~min}$. Helium was used as the carrier gas. Mass spectrometry data were obtained with electron impact ionization at $70 \mathrm{eV}$ (Saturn 2200 ion trap). The peaks on the chromatogram were identified by comparison with the National Institute of Standards and Technology (NIST) gas chromatography-mass spectrometry library. To compare the similarity of the chemical profiles of the various samples beyond a visual comparison of the chromatograms, the relative peak area and the position of each peak on the chromatogram were used to generate a similarity matrix from which to construct a dendrogram, as outlined for the DGGE analysis.

\section{H. elegans larval settlement bioassay}

To determine whether chemical extracts of the biofilms induced or inhibited larval settlement, we examined their effects on the settlement of the larvae of $H$. elegans. Competent $H$. elegans larvae were produced with standard laboratory culture procedures (Qiu and Qian, 1997) and the competence of the larvae was determined (Qian and Pechenik, 1998) before the larval settlement bioassay.

The larval settlement bioassay was performed in 24-well polystyrene plates (BD Falcon, Franklin Lakes, NJ, USA) (Unabia and Hadfield, 1999). The partitioned biofilm extracts were redissolved, aliquoted, and dried to a known mass, and then dissolved in $1 \%$ dimethyl sulfoxide in AFSW. A multispecies biofilm (6d) and 1\% dimethyl sulfoxide in AFSW were used as the positive and negative controls, respectively. Five replicate wells, each receiving 20 competent larvae in $2 \mathrm{ml}$ of test solution, were incubated at $28^{\circ} \mathrm{C}$ in the dark. The percentage of settled larvae were scored after $24 \mathrm{~h}$. The percentage data were subjected to arcsin transformation before statistical analysis by oneway analysis of variance, followed by Tukey's pairwise comparison. 


\section{Results}

Bacterial density in subtidal biofilms

Both age and substratum significantly affected the bacterial density $(P<0.001$; Figure 1$)$. The bacterial density of the biofilms increased over the succession period (20 days) from 5000 to 60000 cells $\mathrm{mm}^{-2}$ on the Petri dishes and from 10000 to 110000 cells mm $\mathrm{mm}^{-2}$ on the granite rock (Figure 1). The bacterial densities of the biofilms developed on granite rock were always higher than those of biofilms developed on Petri dishes.

Bacterial community analysis by DGGE

The number of bands (that is ribotypes) on the DGGE gels (ranging from 12 to 23) did not increase over

\begin{tabular}{lccccc}
\multicolumn{2}{l}{ Two-way ANOVA results } \\
\hline \multicolumn{1}{c}{ SS } & df & ms & F & P \\
\hline Substratum (S) & $1.22 \times 10^{4}$ & 1 & $1.22 \times 10^{4}$ & 591 & $<0.001^{*}$ \\
Age (A) & $1.13 \times 10^{5}$ & 5 & $2.26 \times 10^{4}$ & 1091 & $<0.001^{*}$ \\
$\mathrm{~S} \times \mathrm{A}$ & $1.11 \times 10^{4}$ & 5 & 2213 & 107 & $<0.001^{*}$ \\
\hline
\end{tabular}

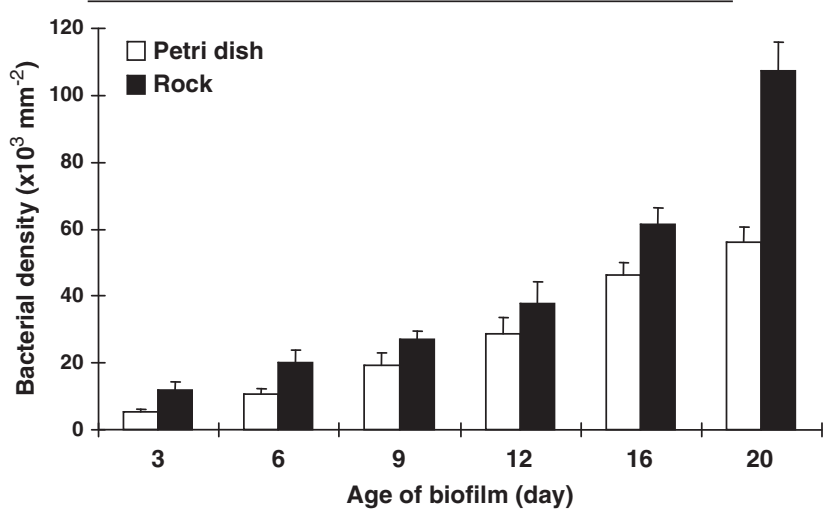

Figure 1 Bacterial density in biofilms developed on Petri dishes (open bars) or granite rock (filled bars) during the succession period. Each bar represents the mean value of triplicate measurements (10 fields per replicate) of biofilm bacterial densities. SS, d.f., ms, and $F$ represent sum of square, degree of freedom, mean square, and $F$ distribution in the table of two-way analysis of variance results. Both the substratum and biofilm age had significant effects on bacterial density (asterisks). time. Except for the 3d biofilms, the young biofilms (6d, 9d) had fewer ribotypes than the old biofilms (16d, 20d). In general, the numbers of bands for the biofilms developed on Petri dishes were higher than those for the biofilms developed on rock. Several bands, unique to the samples of a specific succession time point, were sequenced. Bands a, b, and c (Figure 2) were closely affiliated to Exiguobacterium sp. CrK19 (GQ503330), Exiguobacterium sp. J54CU (GQ901880), and an uncultured $\alpha$-Proteobacterium (FJ356664), respectively. On cluster analysis, the bacterial communities of biofilms of the same age clustered together, with the greatest similarity among the $3 \mathrm{~d}$ biofilms $(\sim 75 \%)$ and the least similarity among the $20 \mathrm{~d}$ biofilms $(\sim 55 \%)$ (Figure 2). The bacterial communities of the young biofilms (3d-9d), regardless the type of substratum, formed a cluster distinct from the cluster formed by the samples from the old biofilms $(16 \mathrm{~d}-20 \mathrm{~d})$, with a similarity of $30 \%$ between the two.

\section{Bacterial community analysis by PhyloChip}

The bacterial composition of the $6 \mathrm{~d}$ biofilm was different from that of the $12 \mathrm{~d}$ biofilm when determined by the PhyloChip method. A total of 158 taxa were detected in the samples, and more taxa were detected in the $12 \mathrm{~d}$ biofilm (123 taxa) than in the $6 \mathrm{~d}$ biofilm (100 taxa). Among the 158 taxa detected, 148 were affiliated to 10 known phyla (Figure 3). Bacteroidetes, Cyanobacteria, Firmicutes, and Proteobacteria were detected in both the $6 \mathrm{~d}$ and 12d biofilms, whereas Acidobacteria and Verrucomicrobia were more diverse in the $12 \mathrm{~d}$ biofilms than in the $6 \mathrm{~d}$ biofilms. The phylum Chloroflexi was detected only in the $6 \mathrm{~d}$ biofilms, whereas the phylum Planctomycetes was detected only in the $12 \mathrm{~d}$ biofilms. The most diverse group of bacteria detected in both the $6 \mathrm{~d}$ and $12 \mathrm{~d}$ biofilms was the Proteobacteria. The occurrences of the different taxa in the two biofilm samples are shown in Supplementary Table 1 . The $\alpha$-Proteobacteria de-

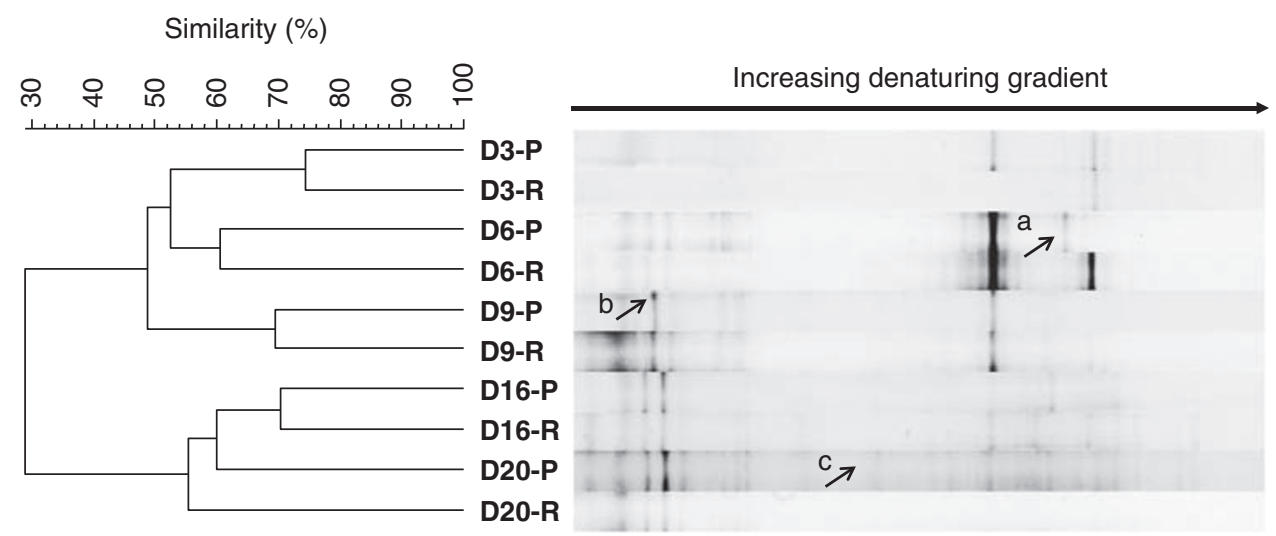

Figure 2 DGGE band patterns (right panel) of 16S rDNA amplicons from bacterial communities of different ages in biofilms developed on Petri dishes (-P) or granite rock (-R). The similarities among the different samples were calculated based on the position and intensity of each band, and are displayed as a dendrogram (left panel). 


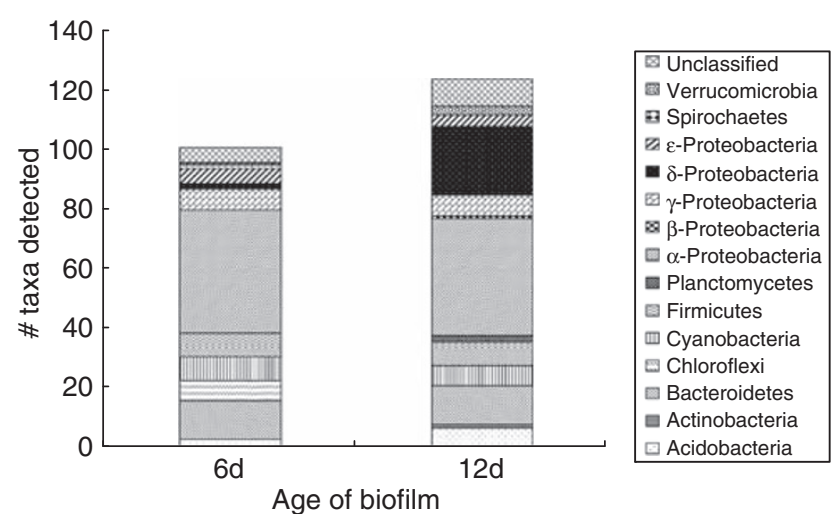

Figure 3 Stacked bars showing the phylum-level compositions of $6 \mathrm{~d}$ and $12 \mathrm{~d}$ biofilms.

tected could be further classified into six known families: Bradyrhizobiaceae (1), Caulobacteraceae (2), Phyllobacteriaceae (4), Rhodobacteraceae (28), Rickettsiaceae (1), and Sphingomonadaceae (12). Among these, members of the Phyllobacteriaceae were detected only in the $12 \mathrm{~d}$ biofilms, whereas members of the Sphingomonadaceae were more diverse in the $6 \mathrm{~d}$ biofilms than in the $12 \mathrm{~d}$ biofilms. Twenty-three $\delta$-Proteobacteria were detected in the $12 \mathrm{~d}$ biofilms, but only two were detected in the $6 \mathrm{~d}$ biofilms. $\beta$-Proteobacteria were detected only in the $12 \mathrm{~d}$ biofilms, whereas $\varepsilon$-Proteobacteria and $\gamma$-Proteobacteria were detected in both the $6 \mathrm{~d}$ and $12 \mathrm{~d}$ biofilms.

\section{Chemical profile analysis of biofilm extracts}

The biofilms developed on different substrata for different times were subjected to solvent extraction and the crude extracts were partitioned into polar (MilliQ water extract) and nonpolar (DCM extract) fractions. The amounts of MilliQ water extracts obtained from the different samples ranged from 1.2 to $4.8 \mathrm{mg}$ and those of the DCM extracts ranged from 33.6 to $50.6 \mathrm{mg}$. More extract was generally obtained from the old biofilms, although no correlation was established between the age of the biofilm or the type of substratum and the amount of extract obtained. Qualitative and quantitative changes were observed in the chemical profiles of the extracts obtained from biofilms of different ages or from different substrata. The chemical compositions of the MilliQ water extracts from biofilms developed on Petri dishes were different from those developed on rock (Table 1; Supplementary Figure 1). Regardless of the type of substratum, the compositions of the MilliQ water extracts from young biofilms resembled each other, but differed from those from old biofilms. These observations were supported by cluster analysis, which showed strong similarity among the MilliQ water extracts from the young biofilms ( $>70 \%$ similarity) and among those from the old biofilms ( $>60 \%$ similarity), but weak similarity between the extracts from biofilms developed on different substrata ( $\sim 55 \%$ ) (Figure $4 a)$. In contrast to the varying chemical compositions of the MilliQ water extracts, little variation was observed among the DCM extracts from biofilms of different ages or originating from different substrata (Figure 4b). Cluster analysis showed that the DCM extracts from biofilms of different ages on rock shared $>80 \%$ similarity, but no clear cluster pattern was observed with respect to the ages of the biofilms (Figure 4b).

A peak-by-peak comparison of the chromatograms of different extracts (Supplementary Figure 1) and the mass spectrometry data for these peaks with data from the NIST gas chromatography-mass spectrometry library (Table 1) showed that some peaks appeared consistently in all MilliQ water and DCM extracts, whereas other peaks were only present on one type of substratum or at a specific biofilm age. The chemical species that could be matched to the NIST library are listed in Table 1.

\section{Larval settlement bioassays}

The larval responses to the extracts of biofilms developed on different substrata were similar for both the MilliQ water and DCM extracts. No larvae settled when exposed to the MilliQ water extract at a concentration of 50 or $100 \mu \mathrm{g} \mathrm{m}^{-1}$. When the concentration was increased to $200 \mu \mathrm{g} \mathrm{ml}^{-1}$, larval settlement was significantly higher than that in the negative control for all MilliQ water extracts, except those from the $6 \mathrm{~d}$ biofilms grown on Petri dishes and the $3 \mathrm{~d}$ biofilms grown on rock (Figure 5a). All the settled larvae developed tentacles and a calcified tube (characteristics of normal settlement and metamorphosis; Figure 6a).

Similarly, no larvae settled when exposed to DCM extracts at $50 \mu \mathrm{g} \mathrm{ml}^{-1}$. When the concentration was increased to $75 \mu \mathrm{g} \mathrm{ml}^{-1}$, the percentage of larval settlement was significantly greater than that in the negative control when the larvae were exposed to DCM extracts from 12-20d biofilms developed on Petri dishes or from 20d biofilms developed on rock (Figure 5b). However, the larvae only developed tentacles but not a calcified tube (the characteristics of abnormal settlement and metamorphosis; Figure 6b). At a concentration of $100 \mu \mathrm{g} \mathrm{ml}^{-1}$, all DCM extracts induced abnormal settlement (Figures 5c and 6b).

\section{Discussion}

Many studies have investigated the succession of microbial communities in natural biofilms (Shimizu et al., 2000; Jackson et al., 2001; Moss et al., 2006), but so far, no strong link has been established between microbial community structure and larval settlement. At the same time, few studies have investigated the chemical compositions of 


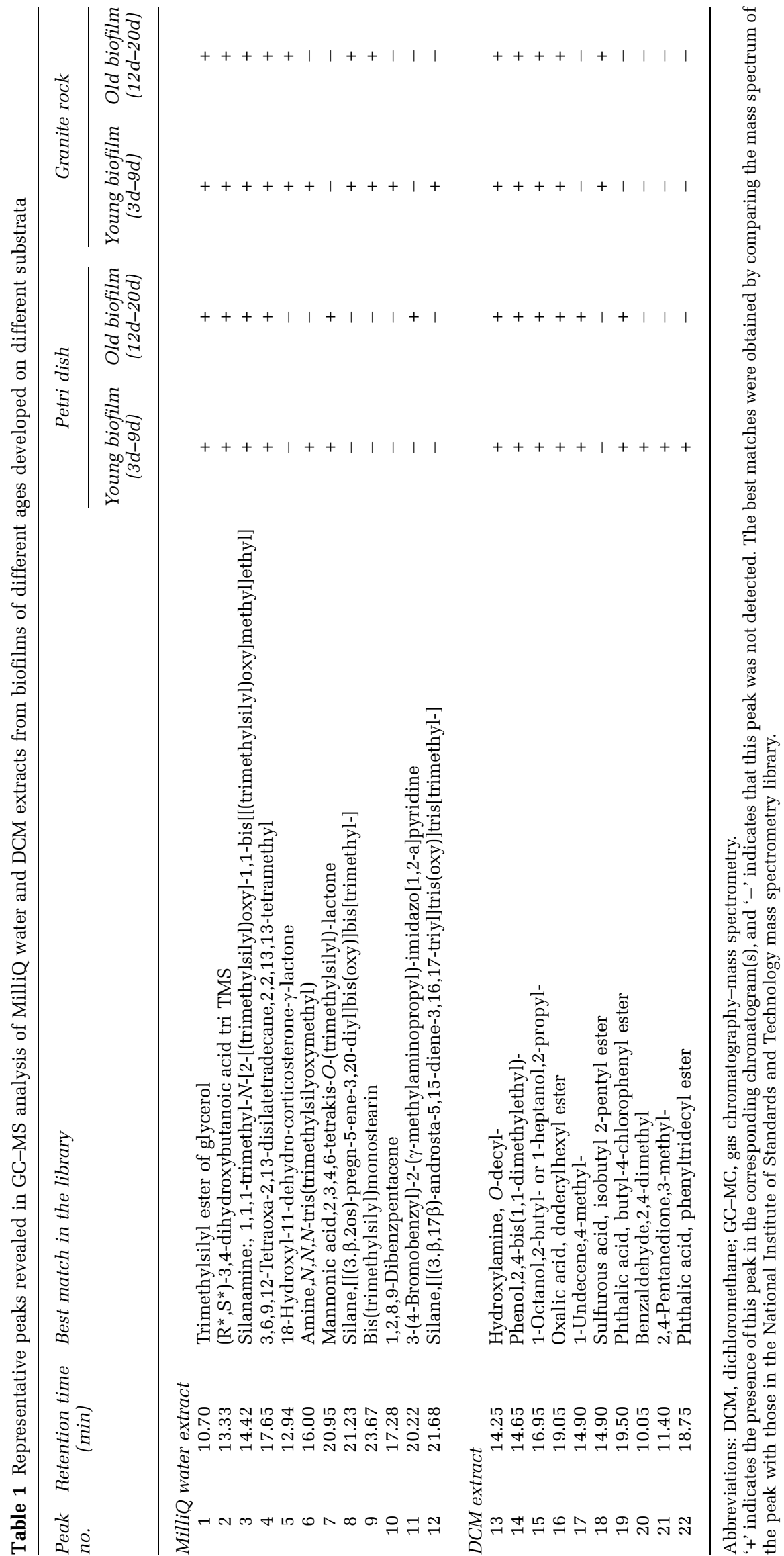



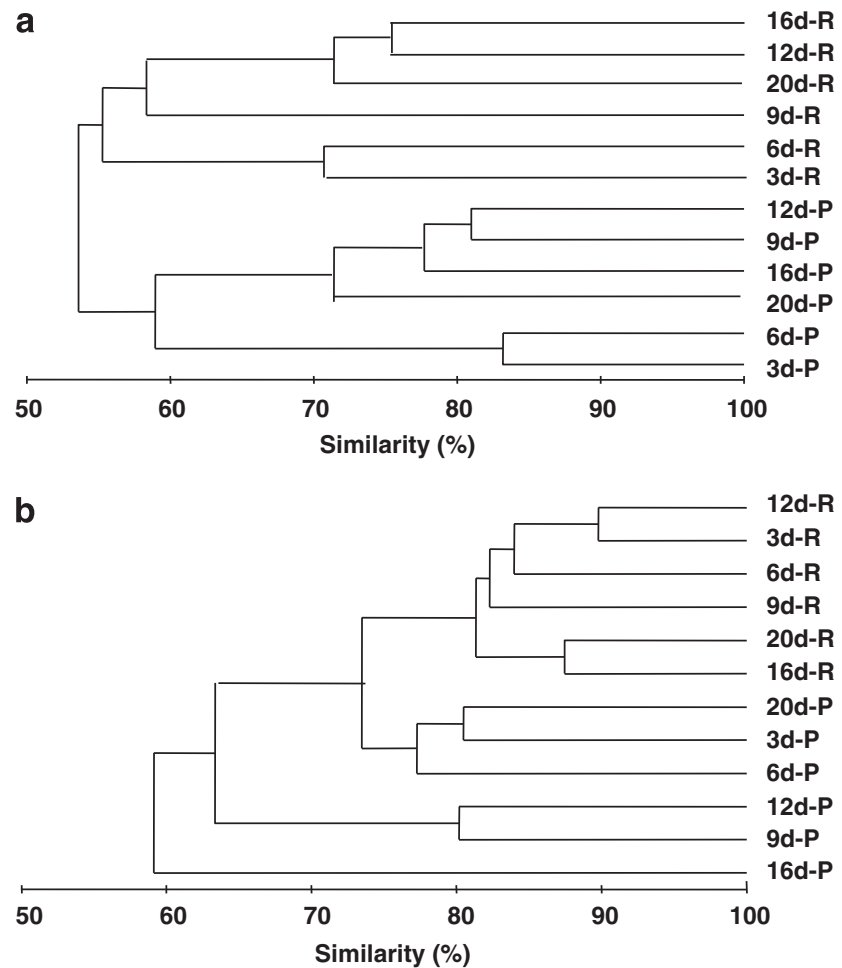

Figure 4 Dendrogram showing the similarities of the chemical compositions of the (a) MilliQ water extracts and (b) DCM extracts from biofilms of different ages $(3 \mathrm{~d}-20 \mathrm{~d})$ developed on Petri dishes $(-\mathrm{P})$ or granite rock (-R).

natural biofilms, although the chemistry of the biofilm may directly mediate larval settlement. In this study, we investigated both the chemical compositions and bacterial community structures of marine subtidal biofilms over a succession period of 20 days and tested the effects of extracts from these biofilms on the larval settlement of $H$. elegans. We also used a natural substratum, granite, in this study to examine whether using Petri dishes (which are usually used in similar studies) as substrate in bioassay produces ecologically relevant results.

Huang and Hadfield (2003) observed a positive correlation between larval settlement and bacterial density and suggested that bacterial density is an important parameter in the induction of the larval settlement of $H$. elegans. However, Qian (1999) demonstrated that after the bacterial density in a biofilm had reached a certain level, reducing the bacterial density by adding antibiotics did not significantly reduce the larval settlement of $H$. elegans, leading to the hypothesis that the larval settlement of $H$. elegans is controlled by the presence of specific cues present in the biofilm, regardless of the density of the bacteria. In our study, we observed increases in the bacterial densities of biofilms over time (Figure 1), which is similar to the findings of many earlier studies (Harder et al., 2002a; Huang and Hadfield, 2003; Lau et al., 2005).
Biofilms developed on granite rock generally had higher bacterial densities than those on Petri dishes (Figure 1). However, the extracts from biofilms that developed on granite rock did not induce higher settlement rates than those from biofilms that developed on Petri dishes (Figures 1 and 6a). These results support the hypothesis that the bacterial density of biofilms does not always correlate directly with the larval settlement of $H$. elegans, indicating the importance of evaluating other biofilm parameters that may contribute to different larval settlement patterns.

Earlier studies have shown that biofilms developed on different artificial substrata, such as concrete, fiberglass, glass, and cembonit, contain unique microbial communities (bacteria, diatoms, fungi, and protozoa), which correlate with the differential settlement of barnacle larvae (Anderson and Underwood, 1994; Faimali et al., 2004; Hung et al., 2008). Similarly, bacterial community structure has been suggested as an indicator of habitat suitability for settling $H$. elegans larvae (Unabia and Hadfield, 1999; Qian et al., 2003; Lau et al., 2005). Our results show that the bacterial community changed more with age than with substratum type (Figure 2). We hypothesize that the substratum affects the initial development of the biofilm and its induction of larval settlement, but the effect of the substratum type diminishes as the biofilm ages. This is supported by Huggett et al. (2009), who showed that biofilms undergo a distinct temporal shift, regardless of the initial surface wetability of the substratum.

Earlier studies (Unabia and Hadfield, 1999; Lau et al., 2002) have isolated bacterial strains that induce $H$. elegans larval settlement. However, the presence of inductive bacterial strains in a natural biofilm does not necessarily explain this biofilm's inductiveness. In this study, we compared the bacterial community structures of young (6d) and old (12d) subtidal biofilms with DGGE and Phylochip. Our results suggest that during biofilm succession, the bacterial community structure shifted and certain phyla were found only in either young or old biofilms. For example, the phylum Chloroflexi was found only in young biofilms. This photoheterotrophic phylum is usually associated with sponges, corals, and filamentous biofilms (Hentschel et al., 2003; Okabe et al., 2005; Ishii et al., 2008; Apprill et al., 2009); some Chloroflexi have been reported to express antisettlement activity against $H$. elegans (Qian et al., 2006). The presence of these inhibitive strains may help to explain the low settlement inductiveness of the young biofilm extracts. Conversely, members of the phylum Planctomycetes were only found in the old biofilms. This result is not surprising because members of Planctomycetes are usually associated with relatively mature communities, such as those that form after cyanobacterial or algal blooms (Brummer et al., 2004; Eiler and Bertilsson, 2004). 
a $\quad 200 \mu \mathrm{g} \mathrm{mL}^{-1}$ Milli Q water extract

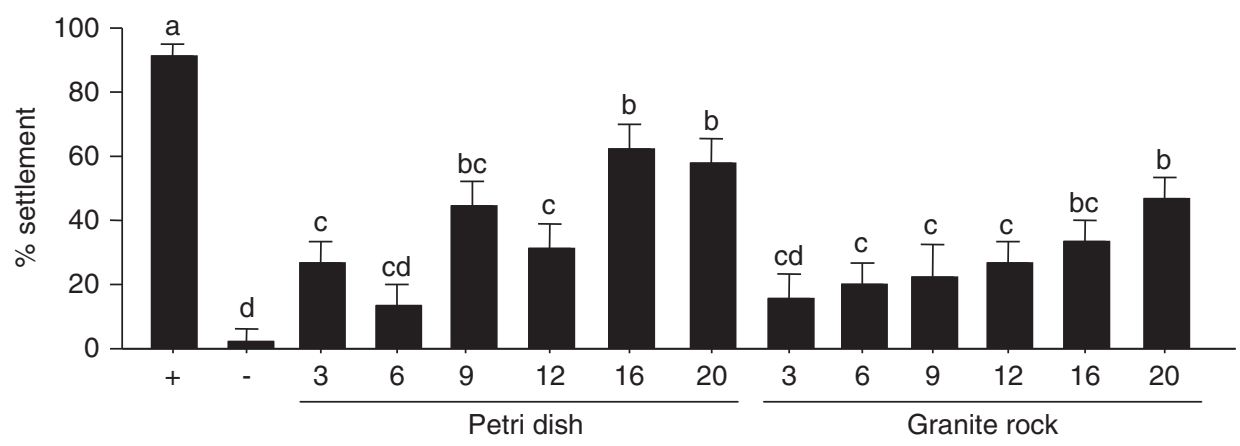

b $\quad 75 \mu \mathrm{g} \mathrm{mL}^{-1}$ DCM extracts

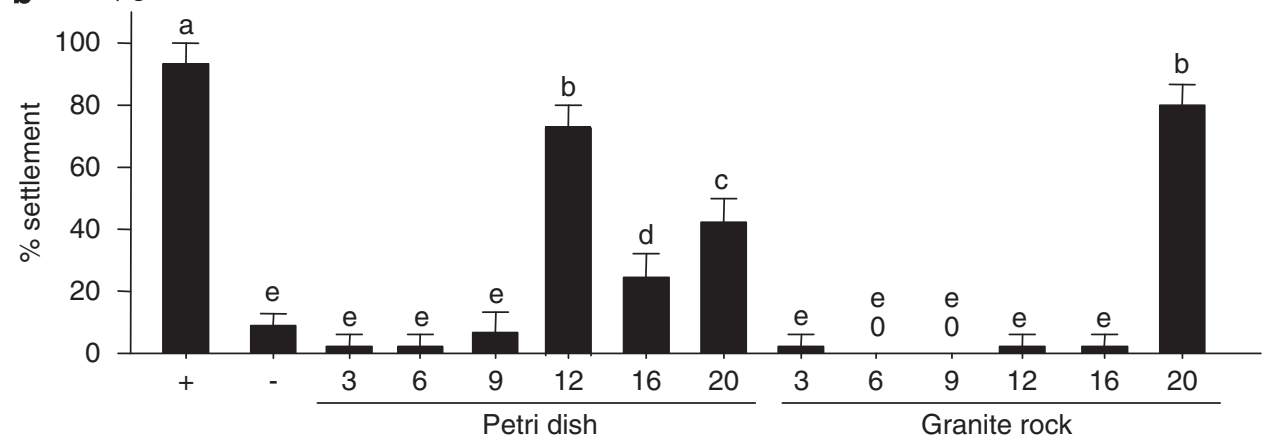

C $\quad 100 \mu \mathrm{g} \mathrm{mL}^{-1} \mathrm{DCM}$ extracts

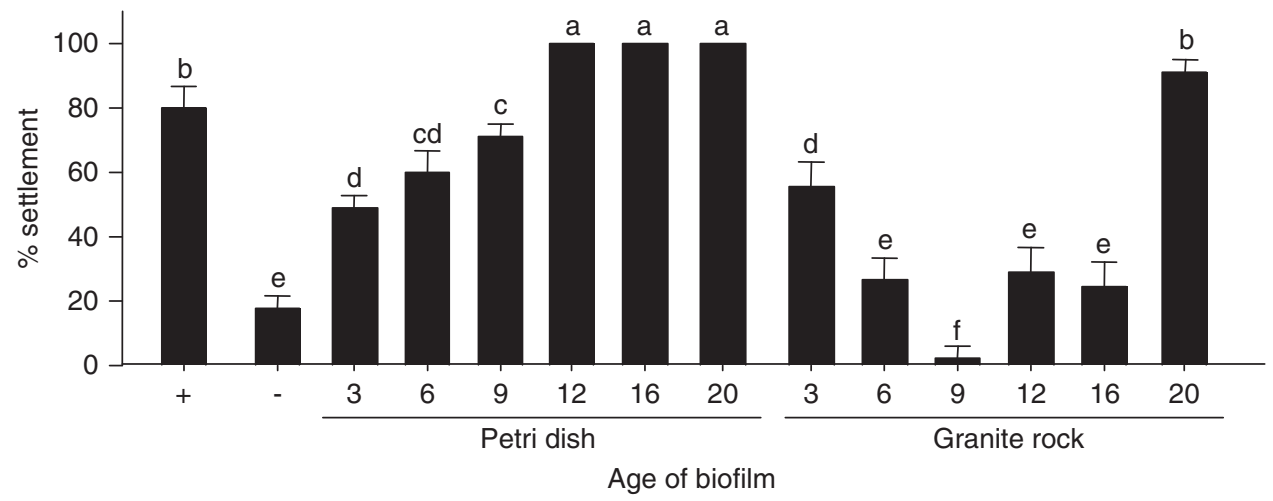

Figure 5 Larval settlement response to (a) $200 \mu \mathrm{g} \mathrm{ml}^{-1}$ MilliQ water extract, (b) $75 \mu \mathrm{g} \mathrm{ml}^{-1}$, and (c) $100 \mu \mathrm{g} \mathrm{ml} \mathrm{H}^{-1} \mathrm{DCM}$ extracts from biofilms of different ages developed on the two substrata. Positive control ( +) was a $6 \mathrm{~d}$ natural biofilm and the negative control ( - ) is $1 \%$ dimethyl sulfoxide. Data are mean \pm s.d. of five replicates.

However, the effects of this group of bacteria on larval settlement have not been documented.

The diversity of the family Sphingomonadaceae was far higher in the young biofilms than in the old biofilms. In fact, it has been suggested that members of the Sphingomonadaceae are pioneers in biofilm formation (Pang and Liu, 2006; Zhang et al., 2006). The family Phyllobacteriaceae was detected only in the old biofilms in our study. Interestingly, Shikuma and Hadfield (2006) observed an increase in Phyllobacteriaceae strains as biofilms aged. $\delta$-Proteobacteria were mainly detected in the old biofilms. Many members of this class are sulfate- or sulfurreducing bacteria usually detected in activated sludge biofilms (Santegoeds et al., 1998; Minz et al., 1999). More research must be undertaken to determine the effects of these groups of bacteria on larval settlement.

The diversity of members of certain bacterial phyla may differ substantially at different points in a succession, and DGGE and PhyloChip might not provide the best phylogenetic resolution. However, both can quickly reveal the general structures and differences in the bacterial communities in young and old biofilms. For example, Exiguobacterium species were unique to $6 \mathrm{~d}$ and $9 \mathrm{~d}$ samples (Figure 2, bands a and b, respectively) and the PhyloChip data confirmed that Exiguobacterium 
a
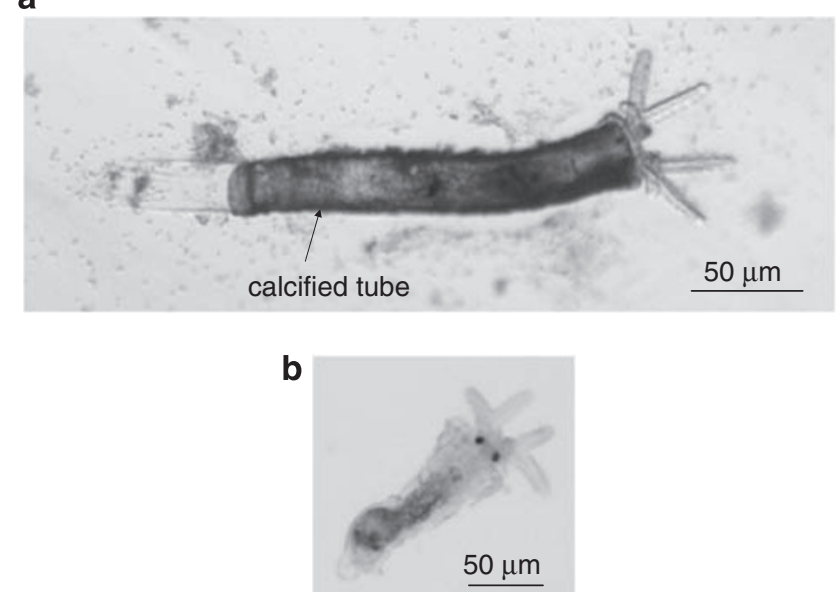

Figure 6 Images of H. elegans larvae undergoing normal (a) and abnormal (b) metamorphosis.

was only detectable in the 6d samples (Supplementary Table 1, the Firmicutes phylum). A more sophisticated method, such as a metagenomic study, could increase the resolution of the community structure and should be one of the future directions in molecular analysis of microbial community of biofilms.

This study is the first to report variations in the chemical compositions of subtidal biofilms over time. The chemical profiles of biofilms of different ages developed on different substrata were highly diverse. Hundreds of peaks were observed in the GC chromatograms of the biofilm extracts, but not all of them could be identified by comparison with the NIST library. This result is expected because natural biofilms are composed of bacteria, diatoms, fungi, and protozoa, and each member can produce a diverse range of metabolites. All the identified peaks were organic molecules, such as hydrocarbons, fatty acids, and ammonia derivatives (Table 1). The involvement of amines (and related chemical derivatives) as neurotransmitters in larval settlement has been reported in several studies (Morse et al., 1979; Yamamoto et al., 1999; Shimizu et al., 2000). In this study, we found ammonia derivatives in the natural biofilms, but the roles of these compounds in $H$. elegans larval settlement require further investigation.

In this study, we did not identify the same natural inductive cues in the biofilms as were reported by Hung et al. (2009), but instead found other fatty acid molecules (Table 1). This is not surprising because the natural biofilms used in this study and those examined by Hung et al. (2009) were developed during different seasons and at different field sites under different environmental conditions. However, it is important to note the similar trends in the larval settlement inductiveness of the biofilm extracts in these two studies. First, the MilliQ water extracts of both studies induced larval settlement in a concentration-dependent manner, although the inductiveness of the MilliQ water extracts in both studies was dissimilar to that of the natural biofilm used as the positive control. In this study, the MilliQ water extracts from the $6 \mathrm{~d}$ biofilm did not induce similar settlement to that induced by the $6 \mathrm{~d}$ live natural biofilm control used in the study of Hung et al. This observation further supports the hypothesis that cues from live biofilms are essential for $H$. elegans larval settlement (Hung et al., 2005) and that the inductive cues for $H$. elegans larval settlement are not restricted to the polar fraction. DCM extracts showed concentration- and biofilm-age-dependent inductiveness but induced abnormal metamorphosis at high concentrations (Figures $5 \mathrm{~b}$ and c). Interestingly, both the fatty acids (inductive cue) isolated in the earlier study (Hung et al., 2009) and a commercial long-chain fatty acid (oleic acid) caused abnormal metamorphosis at concentration of $>150 \mu \mathrm{g} \mathrm{ml}^{-1}$ (unpublished data). These observations suggest that fatty acids might have a role in both the settlement and development of $H$. elegans larvae, but the working concentration in the natural environment requires further study.

The general chemical patterns observed did not provide a precise estimate of the larval settlement patterns. Although the chemical profiles of natural biofilm extracts clustered according to substratum type, we did not see any differences in the percentage settlement of $H$. elegans larvae induced by the chemical extracts derived from the two different substrata. The larval settlement response may vary with quantitative changes in individual chemical compounds. For example, even though the DCM extracts from the $16 \mathrm{~d}$ and $20 \mathrm{~d}$ biofilms (developed on rock) were similar in their chemical profiles, there were many quantitative differences in the chemical compounds of the two biofilm extracts, such as in phthalic acid, phenlyltridecyl ester (Table 1, peak 19), and hydroxylamine, O-decyl(Table 1, peak 13). Quite a number of chemical species, in both the MilliQ water and DCM extracts, showed quantitative increases or decreases over the period of the succession.

On the basis of our previous findings and literature reviews, we strongly believe that inductive chemical cues for the larval settlement of $H$. elegans are produced by many different bacterial families and classes. So far, we cannot link the detected settlement cues to a specific producer. However, we have limited the number of active players. For example, the increase in the quantity of hydroxylamine (a potential settlement cue) suggests an increase in ammonia-oxidizing bacteria in the biofilm during the succession. Specific primers for these active players can be used with a molecular fingerprinting method to profile the community structures of different biofilms, to further investigate how changes in these groups alter the larval settlement response. The results of this study 
indicate that it is crucial to monitor the changes in the chemical composition and bacterial community structure of a biofilm simultaneously to best understand the effects of the biofilm on larval settlement behavior. However, it is unlikely that the overall bacterial community or chemical profiles directly reflect the capacity of natural biofilms to induce larval settlement. Here, we propose that the larval settlement response is regulated by many compounds produced by bacteria or other microbes in natural biofilms, which vary quantitatively and qualitatively over the period of biofilm development. Indeed, the metabolites extracted from biofilms can alter the larval settlement of the polychaete in an inductive (Toonen and Pawlik, 1996; Harder et al., 2002b) or inhibitive manner (Holmstrom et al., 2002; Lee and Qian, 2003). The actual producers of these compounds warrant further investigation. The identification of larval settlement cues using a chemical profiling approach should provide a starting point for the isolation of the actual producers.

\section{Acknowledgements}

This study was supported by a Grant (KZCXZ-YW-T001) from the CAS/SAFEA International Partnership program for Creative Research Team, award (SA-C0040/UK-C0016) of the King Abdullah University of Science and Technology, the Research Grants Councils Grant (662207) of the government of the Hong Kong Special Administrative Region to P-Y Qian, and by a grant from the National Institutes of Health to R Kolter. We acknowledge the help of Dr Klepac-Ceraj of Harvard University in running the microarray experiment.

\section{References}

Anderson MJ, Underwood AJ. (1994). Effects of substratum on the recruitment and development of an intertidal estuarine fouling assemblage. J Exp Mar Bio Ecol 184: 217-236.

Apprill A, Marlow HQ, Martindale MQ, Rappe MS. (2009). The onset of microbial associations in the coral Pocillopora meandrina. ISME J 3: 685-699.

Bodrossy L, Sessitsch A. (2004). Oligonucleotide microarrays in microbial diagnostics. Curr Opin Microbiol 7: 245-254.

Brodie EL, DeSantis TZ, Joyner DC, Baek SM, Larsen JT, Andersen GL et al. (2006). Application of a highdensity oligonucleotide microarray approach to study bacterial population dynamics during uranium reduction and reoxidation. Appl Environ Microbiol 72: 6288-6298.

Brodie EL, DeSantis TZ, Parker JPM, Zubietta IX, Piceno YM, Andersen GL. (2007). Urban aerosols harbor diverse and dynamic bacterial populations. Proc Natl Acad Sci USA 104: 299-304.

Brummer IHM, Felske ADM, Wagner-Dobler I. (2004). Diversity and seasonal changes of uncultured Planctomycetales in river biofilms. Appl Environ Microbiol 70: 5094-5101.
Chiu JMY, Thiyagarajan V, Pechenik JA, Hung OS, Qian PY. (2007). Influence of bacteria and diatoms in biofilms on metamorphosis of the marine slipper limpet Crepidula onyx. Mar Biol 151: 1417-1431.

Clarke K, Warwick R. (2001). Changes in Marine Communities: An Approach to Statistical Analysis and Interpretation, 2nd edn, vol. 1. Primer-E: Plymouth, UK, 172.

Decho AW. (2000). Microbial biofilms in intertidal systems: an overview. Cont Shelf Res 20: 1257-1273.

Dobretsov S, Qian PY. (2006). Facilitation and inhibition of larval attachment of the bryozoan Bugula neritina in association with mono-species and multi-species biofilms. J Exp Mar Biol Ecol 333: 263-274.

Drozd J, Novak J. (1982). Determination of trace hydrophobic volatiles in aqueous media by a technique of multiple stripping and trapping in a closed circuit. Int J Environ Anal Chem 11: 241-249.

Eiler A, Bertilsson S. (2004). Composition of freshwater bacterial communities associated with cyanobacterial blooms in four Swedish lakes. Environ Microbiol 6: 1228-1243.

Faimali M, Garaventa F, Terlizzi A, Chiantore M, CattaneoVietti R. (2004). The interplay of substrate nature and biofilm formation in regulating Balanus amphitrite Darwin, 1854 larval settlement. J Exp Mar Biol Ecol 306: $37-50$.

Harder T, Lam C, Qian PY. (2002a). Induction of larval settlement in the polychaete Hydroides elegans by marine biofilms: an investigation of monospecific diatom films as settlement cues. Mar Ecol Prog Ser 229: 105-112.

Harder T, Lau SCK, Dahms HU, Qian PY. (2002b). Isolation of bacterial metabolites as natural inducers for larval settlement in the marine polychaete Hydroides elegans (Haswell). J Chem Ecol 28: 2029-2043.

Hentschel U, Fieseler L, Wehrl M, Gernert C, Steinert M, Hacker J et al. (2003). Microbial Diversity of Marine Sponges. Springer Verlag: Berlin.

Holmstrom C, Egan S, Franks A, McCloy S, Kjelleberg S. (2002). Antifouling activities expressed by marine surface associated Pseudoalteromonas species. FEMS Microbiol Ecol 41: 47-58.

Huang SY, Hadfield MG. (2003). Composition and density of bacterial biofilms determine larval settlement of the polychaete Hydroides elegans. Mar Ecol Prog Ser 260: 161-172.

Huggett MJ, Nedved BT, Hadfield MG. (2009). Effects of initial surface wettability on biofilm formation and subsequent settlement of Hydroides elegans. Biofouling 25: 387-399.

Hung OS, Lee OO, Thiyagarajan V, He HP, Xu Y, Chung HC et al. (2009). Characterization of cues from natural multi-species biofilms that induce larval attachment of the polychaete Hydroides elegans. Aquat Biol 4: 253-262.

Hung OS, Thiyagarajan V, Qian PY. (2008). Preferential attachment of barnacle larvae to natural multi-species biofilms: does surface wettability matter? J Exp Mar Bio Ecol 361: 36-41.

Hung OS, Thiyagarajan V, Wu RSS, Qian PY. (2005). Effect of ultraviolet radiation on biofilms and subsequent larval settlement of Hydroides elegans. Mar Ecol Prog Ser 304: 155-166. 
Hung OS, Thiyagarajan V, Zhang R, Wu RSS, Qian PY. (2007). Attachment of Balanus amphitrite larvae to biofilms originating from contrasting environments. Mar Ecol Prog Ser 333: 229-242.

Ishii K, Fukui M, Takii S. (2000). Microbial succession during a composting process as evaluated by denaturing gradient gel electrophoresis analysis. J Appl Microbiol 89: 768-777.

Ishii S, Shimoyama T, Hotta Y, Watanabe K. (2008). Characterization of a filamentous biofilm community established in a cellulose-fed microbial fuel cell. BMC Microbiol 8: 1-12.

Jackson CR, Churchill PF, Roden EE. (2001). Successional changes in bacterial assemblage structure during epilithic biofilm development. Ecology 82: 555-566.

Lau SCK, Mak KKW, Chen F, Qian PY. (2002). Bioactivity of bacterial strains isolated from marine biofilms in Hong Kong waters for the induction of larval settlement in the marine polychaete Hydroides elegans. Mar Ecol Prog Ser 226: 301-310.

Lau SCK, Thiyagarajan V, Cheung SCK, Qian PY. (2005). Roles of bacterial community composition in biofilms as a mediator for larval settlement of three marine invertebrates. Aquat Microbial Ecol 38: 41-51.

Lee OO, Qian PY. (2003). Chemical control of bacterial epibiosis and larval settlement of Hydroides elegans in the red sponge Mycale adherens. Biofouling 19: $171-180$

Maki JS, Rittschof D, Costlow JD, Mitchell R. (1988). Inhibition of attachment of larval barnacles, Balanus amphitrite, by bacterial surface-films. Mar Biol 97: 199-206.

Marshall P, Bowden G. (2000). Microbial community interactions in biofilms. In: Allison DG GP, LappinScott HM, Wilson M (eds). Community Structure and Co-operation in Biofilms: Fifty-Ninth Symposium of the Society for General Microbiology. Cambridge University Press, Cambridge, UK, pp 167-198.

Minz D, Flax JL, Green SJ, Muyzer G, Cohen Y, Wagner M et al. (1999). Diversity of sulfate-reducing bacteria in oxic and anoxic regions of a microbial mat characterized by comparative analysis of dissimilatory sulfite reductase genes. Appl Environ Microbiol 65: 4666-4671.

Mitchell R, Maki J. (1988). Microbial surface films and their influence on larval settlement and metamorphosis in the marine environment. In: Thompson M, Sarojini R, Nagabushanam R (eds). Marine Biodeterioration: Advanced Techniques Applicable to the Indian Ocean. Oxford and IBH Publishing, New Delhi, India. pp 489-497.

Monds RD, O'Toole GA. (2009). The developmental model of microbial biofilms: ten years of a paradigm up for review. Trends Microbiol 17: 73-87.

Morse DE, Hooker N, Duncan H, Jensen L. (1979). Gammaaminobutyric acid, a neurotransmitter, induces planktonic abalone larvae to settle and begin metamorphosis. Science 204: 407-410.

Moss JA, Nocker A, Lepo JE, Snyder RA. (2006). Stability and change in estuarine biofilm bacterial community diversity. Appl Environ Microbiol 72: 5679-5688.

Muyzer G, Hottentr ger S, Teske A, Wawer C. (1996). Denaturing Gradient Gel Electrophoresis of PCRAmplified 165 rDNA-A New Molecular Approach to Analyse the Genetic Diversity of Mixed Microbial Communities, vol. 3. Kluwer Academic, Dordrecht, The Netherlands, pp 1-23.
Nocker A, Lepo JE, Martin LL, Snyder RA. (2007). Response of estuarine biofilm microbial community development to changes in dissolved oxygen and nutrient concentrations. Microbial Ecol 54: $532-542$

Okabe S, Kindaichi T, Ito T. (2005). Fate of C-14-labeled microbial products derived from nitrifying bacteria in autotrophic nitrifying biofilms. Appl Environ Microbiol 71: 3987-3994.

Pang CM, Liu WT. (2006). Biological filtration limits carbon availability and affects downstream biofilm formation and community structure. Appl Environ Microbiol 72: 5702-5712.

Pawlik JR. (1992). Chemical ecology of the settlement of benthic marine invertebrates. Oceanogr Mar Biol 30: 273-335.

Qian PY. (1999). Larval settlement of polychaetes. Hydrobiologia 402: 239-253.

Qian PY, Dobretsov S, Dahms HU, Pawlik J. (2006). Antifouling activity and microbial diversity of two congeneric sponges Callyspongia spp. from Hong Kong and the Bahamas. Mar Ecol Prog Ser 324: 151-165.

Qian PY, Pechenik JA. (1998). Effects of larval starvation and delayed metamorphosis on juvenile survival and growth of the tube-dwelling polychaete Hydroides elegans (Haswell). J Exp Mar Bio Ecol 227: 169-185.

Qian PY, Thiyagarajan V, Lau SCK, Cheung SCK. (2003). Relationship between bacterial community profile in biofilm and attachment of the acorn barnacle Balanus amphitrite. Aquat Microbial Ecol 33: 225-237.

Qiu JW, Qian PY. (1997). Combined effects of salinity, temperature and food on early development of the polychaete Hydroides elegans. Mar Ecol Prog Ser 152: 79-88.

Santegoeds CM, Ferdelman TG, Muyzer G, de Beer D. (1998). Structural and functional dynamics of sulfate-reducing populations in bacterial biofilms. Appl Environ Microbiol 64: 3731-3739.

Shikuma N, Hadfield M. (2006). Temporal variation of an initial marine biofilm community and its effects on larval settlement and metamorphosis of the tubeworm Hydroides elegans. Biofilms 2: 231-238.

Shimizu K, Hunter E, Fusetani N. (2000). Localisation of biogenic amines in larvae of Bugula neritina (Bryozoa: Cheilostomatida) and their effects on settlement. Mar Biol 136: 1-9.

Smart K, Smart H, Jackson C. (2008). The effects of fine scale environmental variation on microbial community structure and function in aquatic environments. Environ Microbiol Res Trends, 101-124 Nova Science.

Steinberg PD, De Nys R, Kjelleberg S. (2002). Chemical cues for surface colonization. J Chem Ecol 28: 1935-1951.

Tamburri MN, Zimmerfaust RK, Tamplin ML. (1992). Natural sources and properties of chemical inducers mediating settlement of oyster larvae-a reexamination. Biol Bull 183: 327-338.

Toonen RJ, Pawlik JR. (1996). Settlement of the tube worm Hydroides dianthus (Polychaeta: Serpulidae): Cues for gregarious settlement. Mar Biol 126: 725-733.

Unabia CRC, Hadfield MG. (1999). Role of bacteria in larval settlement and metamorphosis of the polychaete Hydroides elegans. Mar Biol 133: 55-64.

Wieczorek SK, Murray AWA, Todd CD. (1996). Seasonal variation in the effects of hard substratum biofilming 
on settlement of marine invertebrate larvae. Biofouling 10: 309-330.

Wieczorek SK, Todd CD. (1997). Inhibition and facilitation of bryozoan and ascidian settlement by natural multispecies biofilms: effects of film age and the roles of active and passive larval attachment. Mar Biol 128: 463-473.

Yamamoto H, Shimizu K, Tachibana A, Fusetani N. (1999). Roles of dopamine and serotonin in larval attachment of the barnacle, Balanus amphitrite. J Exp Zool 284: 746-758.

Zhang K, Choi H, Dionysiou DD, Sorial GA, Oerther DB. (2006). Identifying pioneer bacterial species responsible for biofouling membrane bioreactors. Environ Microbiol 8: 433-440.

Zhou JZ, Bruns MA, Tiedje JM. (1996). DNA recovery from soils of diverse composition. Appl Environ Microbiol 62: $316-322$.

Supplementary Information accompanies the paper on The ISME Journal website (http://www.nature.com/ismej) 